\title{
High-pressure adsorptive storage of hydrogen in MIL-101 (Cr) and AX-21 for mobile applications: cryocharging and cryokinetics
}

Nuno Bimbo ${ }^{\mathrm{a}}$, Wesley Xu ${ }^{\mathrm{b}}$, Jessica E Sharpe ${ }^{\mathrm{b}, \mathrm{c}, 1}$, Valeska P Ting ${ }^{\mathrm{b}}$ and Timothy J Mays ${ }^{\mathrm{b} *}$

${ }^{a}$ Department of Engineering, Lancaster University, Bailrigg, Lancaster, LA14YR, United Kingdom

${ }^{\mathrm{b}}$ Department of Chemical Engineering, University of Bath, Claverton Down, Bath, BA2 7AY, United Kingdom

${ }^{\mathrm{c}}$ Centre for Doctoral Training in Sustainable Chemical Technologies, University of Bath, Claverton Down, Bath, BA2 7AY, United Kingdom

${ }^{1}$ Present address - Newton Europe, Engineering Consultancy, Abingdon, OX13 5FE, United Kingdom

*Corresponding author:

Dr Timothy J Mays

Postal address: Department of Chemical Engineering, University of Bath, Claverton Down, BA2

7AY, Bath, United Kingdom

Email: T.J.Mays@bath.ac.uk

Telephone: +44 (0) 1225386528

Other author's email addresses:

Dr Nuno Bimbo - n.bimbo@lancaster.ac.uk

Wesley Xu - wx244@bath.ac.uk

Dr Jessica E Sharpe - jesssharpe @ hotmail.co.uk

Dr Valeska P Ting - V.Ting@ bath.ac.uk 


\begin{abstract}
Current state-of-the-art methods consist of containing high-pressure compressed hydrogen in composite cylinders, with solid-state hydrogen storage materials an alternative that could improve on storage performance by enhancing volumetric densities. A new strategy that uses cryogenic temperatures to load hydrogen (cryocharging) is proposed and analysed in this work, comparing densities and final storage pressures for empty cylinders and containers with the high-surface area materials MIL-101 (Cr) and AX-21. Results show cryocharging as a viable option, as it can substantially lower the charging (at $77 \mathrm{~K}$ ) and final pressures (at $298 \mathrm{~K}$ ) for the majority of the cases considered. Kinetics are an equally important requirement for hydrogen storage systems, so the effective diffusivities at these conditions for both materials were calculated, and showed values comparable to the ones estimated in metal-organic frameworks and zeolites from quasielastic neutron scattering and molecular simulations. High-surface area materials tailored for hydrogen storage are a promising route for storage in mobile applications and results show that cryocharging is a promising strategy for hydrogen storage systems, since it increases volumetric densities and avoids energy penalties of operating at high pressures and/or low temperatures.
\end{abstract}




\section{Introduction}

The environmental impacts of our current use of energy are becoming alarming, as combustion of fossil fuels creates a number of issues, the most important of which is global anthropogenic climate change. Climate scientists have pointed out that we are reaching dangerous levels of greenhouse gases in the atmosphere, which could mean an increase in the global temperature by more than 2 ${ }^{\circ} \mathrm{C}$, causing irreversible damage to life on Earth [1]. Added to this, fossil fuels are unequally distributed on Earth, so there are geopolitical drivers for governments to increase their energy security and be less reliant on external sources of energy.

In this context, hydrogen energy is a promising sustainable energy technology, as it can help solve some of these issues. Hydrogen energy is currently considered for a number of uses, including as a means of energy storage for the electric grid, but its main appeal is as an alternative fuel for the transport sector. The transport sector is heavily reliant on oil and needs to be decarbonised, as it currently accounts for about $13 \%$ of all greenhouse gas emissions, so alternative fuels with a lower carbon footprint are much need [1]. Hydrogen puts forward an interesting case to serve as an alternative fuel, as it is the chemical fuel with the highest energy density on a gravimetric basis, with a lower heating value of $120 \mathrm{MJ} \mathrm{kg}^{-1}$ (compared with 40-50 $\mathrm{MJ} \mathrm{kg}^{-1}$ for most hydrocarbon fuels, including petrol and diesel) [2]; it produces energy cleanly, as oxidation of pure hydrogen with oxygen only yields water [3]; it can be used electrochemically in a fuel cell, which is considered a superior technology to internal combustion engines, due to its inherent higher efficiency [4]; and is abundant on the Earth, being the third most common element on its crust, in chemical compounds, including water, biomass and hydrocarbons [5, 6]. Molecular hydrogen $\left(\mathrm{H}_{2}\right)$ does not exist freely in nature, which means that energy will always have to be used to produce it but its abundance means that there is a multitude of production pathways [7]. This means that $\mathrm{H}_{2}$ is an energy vector, not a primary source of energy, as it can only yield as much energy as was used to produce it in the first place [2]. In addition to this, there are technological difficulties in hydrogen energy (including in efficiencies in production and use) as well as social and economic shortcomings, ranging from acceptance of the technology to cost [8,9]. One decisive technological barrier is hydrogen storage - how to store hydrogen in an efficient, safe and affordable way. The difficulty is due to the intrinsic low density of $\left(\mathrm{H}_{2}\right)$ which is a very weakly interacting molecule, as reflected in its density at standard pressure and temperature $\left(0.089885 \mathrm{~kg} \mathrm{~m}^{-3}\right)$ and its extremely 
low normal boiling and melting temperatures of 20.28 and $14.01 \mathrm{~K}$, respectively [2, 10]. As a liquid, hydrogen's density ranges from 33 to $77 \mathrm{~kg} \mathrm{~m}^{-3}$ [10] (compared to liquid water's density at $298 \mathrm{~K}$ and $0.1 \mathrm{MPa}$ of $997.09 \mathrm{~kg} \mathrm{~m}^{-3}$ [11]) and even as a solid, it only has a density of $87 \mathrm{~kg} \mathrm{~m}^{-3}$ (at $4 \mathrm{~K}$ and $0 \mathrm{MPa}$ ) [12], which is less than $10 \%$ of the density of ice $\left(917 \mathrm{~kg} \mathrm{~m}^{-3}\right)$.

Fuel cell electric vehicles that run on hydrogen are one of the most promising technologies in energy efficient transport, with merits including zero emissions at point-of-use and a multitude of hydrogen-producing pathways, with a zero-emission fuel across its life cycle possible if sustainable sources are used in production. Arguably the most difficult technical challenge in hydrogen-fuel cell vehicles is the design of safe and efficient strategies for onboard storage of hydrogen. For mobile applications, space is at a premium, so the emphasis is on increasing hydrogen's volumetric density. Current state-of-the-art for hydrogen storage in mobile applications is compression in high-pressure cylinders. This currently consists of storage at room temperature at $70 \mathrm{MPa}$ in a type IV cylinder. Type IV cylinders are composite cylinders with a polymer liner, which is usually high density poly(ethylene), HDPE. This storage method is used in the forthcoming Toyota Mirai hydrogen fuel cell vehicle [13]. One option to improve on the current state-of-the-art is to incorporate solid-state storage materials for hydrogen storage to improve on volumetric densities, so lowering the occupied volume or diminishing the operating pressure for equal amounts stored. Adsorbent materials, with high-surface areas and uptakes for hydrogen could be incorporated in high-pressure cylinders, and one design alternative is to use adsorbent materials as liners in high-pressure tanks. Using adsorbent materials as liners could offer promising features, including improved thermal and mechanical properties in addition to an improvement on volumetric densities, as hydrogen is adsorbed into the solid-state materials. Additional complementary benefits are in safety, as empty cylinders that discharge high-pressure cylinders can have a long range flame (due to large flowrates from high pressures of hydrogen within the cylinder), in case of ignition upon catastrophic failure.

Designing hybrid high-pressure hydrogen cylinders which combine adsorbent materials as liners is heavily reliant on the properties of the materials. Solid-state hydrogen storage material requirements have been highlighted in recent reports [14] and by the US Department of Energy, as exemplified in their Annual Merit Review [15]. The DOE has enumerated a number of 
requirements, which range from volumetric and gravimetric densities, minimum and maximum delivery temperature to a fuel cell, minimum and maximum pressure, onboard efficiency, cycle life, loss of hydrogen, purity of hydrogen required and fill times, among others. So far, none of the materials, adsorbents or others, have completely fulfilled the requirements, so work on developing and testing new materials is ongoing.

There are limitations for hybrid storage systems with adsorbent materials within them. Operating conditions are important, as adsorptive storage of hydrogen is only significant at cryogenic temperatures and the standard is to use liquid nitrogen temperature $(77 \mathrm{~K})$, which is affordable and easily accessible. The adsorbents considered for hydrogen storage are highly porous, but they still have an inaccessible solid volume that will displace storage volume in the container. It has been shown that there is an optimum pressure range to incorporate adsorbent materials in tanks, which is independent of how much adsorbent is incorporated $[16,17]$. The gains in adsorption are more pronounced in the low pressure region, and eventually a pressure is reached (the "break-even pressure" $([16,17]))$ at which there is more hydrogen stored in an empty cylinder of equivalent size. If adsorbents are used in hybrid storage systems, the likely operating conditions are cryogenic temperatures and moderate pressures, certainly lower than $70 \mathrm{MPa}$.

Compression at room temperature incurs a high energy penalty (compression of hydrogen to 70 MPa requires approximately $18 \mathrm{MJ}$ per $\mathrm{kg} \mathrm{H}_{2}$, which is $15 \%$ of its lower heating value) [18]. Cryocharging the hydrogen cylinders could be a potential solution to reduce the energy penalty, as the pressures involved are much lower. Cryocharging is the charging of compressed hydrogen cylinders at cryogenic temperatures, hence lowering the loading pressures needed to obtain high volumetric densities. As cylinders are then returned to ambient temperatures, there is no need to maintain cryogenic temperatures, so no insulation is required. In this work, cryocharging was assessed by determining the pressures needed to fill hydrogen tanks at $77 \mathrm{~K}$ and comparing the same conditions using hybrid systems, with both an activated carbon (AX-21) and a metal-organic framework (MIL-101 (Cr)). Three different scenarios were used - charging at $0.1 \mathrm{MPa}$ and $77 \mathrm{~K}$ and calculating densities at $298 \mathrm{~K}$, charging to obtain an equal density to a $35 \mathrm{MPa}$ storage cylinder $\left(23.3 \mathrm{~kg} \mathrm{~m}^{-3}\right)$ and to obtain a density equal to gas in a $70 \mathrm{MPa}$ cylinder $\left(39.2 \mathrm{~kg} \mathrm{~m}^{-3}\right)$. The working volumetric capacity, which is calculated based at a charging pressure of 6.5 and $3.5 \mathrm{MPa}$ and a 
delivery pressure of $0.5 \mathrm{MPa}$ was determined at a range of temperatures. As fast charging and discharging are needed for practical applications, the kinetics for both adsorbents at these operating conditions - high-pressures and cryogenic temperatures - were modelled using the linear-driving force model to estimate mass transfer coefficients and effective intraparticle (or transport) diffusivities.

\section{Materials and Methodology}

The materials used in this work were metal-organic framework MIL-101 (Cr) and activated carbon AX-21. These material are chosen as representatives of high-surface area sorbents. AX-21 is a very high-surface area material and one of the most studied activated carbons to date [19]. It is produced from coconut shell precursors treated with $\mathrm{KOH} \mathrm{[19]} \mathrm{and} \mathrm{is} \mathrm{commercially} \mathrm{available,}$ having been acquired from Anderson Development Company. MIL-101 (Cr) is a high-surface area metal-organic framework, with high hydrogen capacity and good stability [20]. It is predominantly mesoporous, with the crystal structure showing a tri-modal pore size distribution, with sizes of 0.7 , 2.9 and $3.4 \mathrm{~nm}$ [21]. The MIL-101 (Cr) was synthesised following the procedure from Sharpe et al. [22]. Both these materials have been fully characterised in our laboratory [23]. The hydrogen isotherms were collected from temperatures ranging from 77 to $298 \mathrm{~K}$ and for pressures up to 18 MPa and were previously published [24]. Modelling of the isotherms was carried out using the non-linear fitting tool available in Origin Pro 9.1 (OriginLab Corporation, Northampton, MA, USA). The bulk density of hydrogen was modelled using the data available from the NIST Webbook of Chemistry [25], which is based on the Leachman equation of state, the best available equation of state for hydrogen [10]. For computational ease, the bulk density obtained from NIST was fitted with a rational function. The isotherms were fitted using a methodology that distinguishes between excess (eq 1), absolute (eq 2) and total adsorption (eq 3) and assumes a constant density of adsorbate [22, 24, 26-28].

$$
\begin{aligned}
& m_{\mathrm{e}}=\rho_{\mathrm{a}} \theta V_{\mathrm{p}}-\rho_{\mathrm{b}} \theta V_{\mathrm{p}} \leftrightarrow\left(\rho_{\mathrm{a}}-\rho_{\mathrm{b}}\right) \theta V_{\mathrm{p}} \\
& m_{\mathrm{a}}=m_{\mathrm{e}}+\rho_{\mathrm{b}} \theta V_{\mathrm{p}} \leftrightarrow \rho_{\mathrm{a}} \theta V_{\mathrm{p}} \\
& m_{\mathrm{t}}=m_{\mathrm{e}}+\rho_{\mathrm{b}} V_{\mathrm{p}} \leftrightarrow \rho_{\mathrm{a}} \theta V_{\mathrm{p}}+\rho_{\mathrm{b}} V_{\mathrm{p}}(1-\theta)
\end{aligned}
$$


where $m_{\mathrm{e}}$ is excess adsorption, $m_{\mathrm{a}}$ is absolute adsorption (which refers to the adsorbate), $m_{\mathrm{t}}$ is total adsorption (which refers to the total amount in the pore space), $\rho_{a}$ is the density of the adsorbed phase, $\rho_{\mathrm{b}}$ is the density of the bulk phase, $\theta$ is the fractional filling of the micropore, and $V_{\mathrm{p}}$ is the pore volume. The units for $m_{\mathrm{e}}, m_{\mathrm{a}}$ and $m_{\mathrm{t}}$ are wt. \%, which is mass of hydrogen over mass of degassed sample, the units for $\rho_{\mathrm{a}}$ and $\rho_{\mathrm{b}}$ are $\mathrm{kg} \mathrm{m}^{-3}$, the filling function $\theta$ is dimensionless and $V_{\mathrm{p}}$ is in units of $\mathrm{cm}^{3} \mathrm{~g}^{-1}$.

Excess hydrogen isotherms for the AX-21 from 90 to $298 \mathrm{~K}$ and up to $18 \mathrm{MPa}$ and for the MIL$101(\mathrm{Cr})$ from 77 to $292 \mathrm{~K}$ and up to $12 \mathrm{MPa}$ were analysed and modelled, with the fractional filling $\theta$ modelled using the Tóth equation (eq. 4) [29-34],

$$
\theta=\frac{b P}{\left[1+(b P)^{c}\right]^{1 / c}}
$$

In eq. $4, b$ is the Tóth affinity parameter, $P$ is absolute pressure and $c$ is the Tóth heterogeneity parameter. All the parameters are assumed to be constant with temperature, except for the Tóth affinity parameter $b$, which was assumed to follow a van't Hoff dependency (eq. 5).

$$
b=b_{0} e^{\left(\frac{Q_{s t}}{R T}\right)}
$$

In eq.5, $b_{0}$ is the pre-exponential or entropic parameter ( $b$ and $b_{0}$ are in units of inverse pressure, say $\mathrm{MPa}^{-1}$ ), $Q_{\mathrm{st}}$ is the energy or enthalpic parameter (in units of $\mathrm{kJ} \mathrm{mol}^{-1}$ ), $R$ is the molar gas constant $\left(0.008314 \mathrm{~kJ} \mathrm{~mol}^{-1}\right)$ and $T$ is absolute temperature in $\mathrm{K}$.

The isotherm data were acquired using a volumetric sorption equipment Hiden HTP-1 (Hiden Isochema, Warrington, UK), which also records the real-time uptake, temperature and pressure of the sample. This kinetic data (uptake as a function of time) were modelled using the linear-driving force (LDF) equation. The LDF equation was introduced by Gleuckauf and Coates $[35,36]$ and is shown in eq. 6.

$$
\left(\frac{\partial n}{\partial t}\right)_{T}=k\left(n_{2}-n(t)\right)
$$


where $n$ is amount adsorbed, $t$ is time, $n_{2}$ is the equilibrium amount (for $t \rightarrow \infty$ ), $n(t)$ is amount adsorbed at time $t$ and $k$ is the mass transfer coefficient (MTC) for the LDF model. Integration of eq. 6 using the boundary condition $n=n_{1}$ at $t=t_{0}$ yields eq. 7 .

$$
n(t)=n_{2}-e^{\left(-k\left(t-t_{0}\right)\right)}\left(n_{2}-n_{1}\right)
$$

For a volumetric sorption experiment, a pressure step is introduced in the sample and the amount adsorbed changes as a function of time. Mass transfer into the sample will be driven by this pressure step. Since the sample holder is a known volume and the sample has a known skeletal density, the gas that is adsorbed by the sample can be calculated from a mass balance to yield the excess uptake. Because of the changing concentration at the surface of the adsorbent particle, a correction has to be done to the eq. 7 in volumetric experiments [37,38], where the fraction present in the adsorptive that is ultimately adsorbed is taken into account. The correction in the LDF model is shown in eq. 8 .

$$
n(t)=n_{2}-e^{\left(-\Lambda k\left(t-t_{0}\right)\right)}\left(n_{2}-n_{1}\right)
$$

where $\Lambda$ is the fraction of sorbate present that is ultimately adsorbed, calculated from the initial and final amounts of moles in the bulk adsorptive, as shown in eq. $9, n_{o}$ is the amount of moles in the adsorptive at instant $t=0$ and $n_{\infty}$ is the number of moles in the adsorptive at equilibrium $(t \rightarrow$ $\infty)$.

$$
\Lambda=\frac{n_{0}-n_{\infty}}{n_{0}}
$$

The fitting of the kinetic data was done using the non-linear fitting tool in Origin Pro 9.1, with $n_{0}$ and $t_{0}$ fixed to the initial amount and the initial time, respectively. This was done for every pressure step in the isotherm. All the kinetic data for the AX-21 at $90 \mathrm{~K}$ and from the MIL-101 (Cr) at 77 and $90 \mathrm{~K}$ were analysed with this method. 
Sample imaging was done using a JEOL 6480 LV scanning electron microscope, after dispersing the sample on a highly ordered pyrolytic graphite background. The resulting images were treated with Image J [39] to obtain particle sizes, first by converting to a black and white image and identifying the dispersed particles and their average area with the software. The black and white figures and the results of the image treatment are shown in Supplementary Information.

\section{Results and Discussion}

The hydrogen isotherms were modelled using a methodology developed at Bath, and including recent developments that distinguish between total, absolute and excess and assume a constant density of adsorbate [16, 22, 24, 26, 27]. Recently, the same methodology was applied to highpressure methane isotherms to determine total amounts and it was found that methane can have very high adsorbed densities and energy densities comparable to methanol [23]. The $\mathrm{H}_{2}$ excess isotherms for both materials were fitted to eq. 1 and the results are shown in Figure 1.
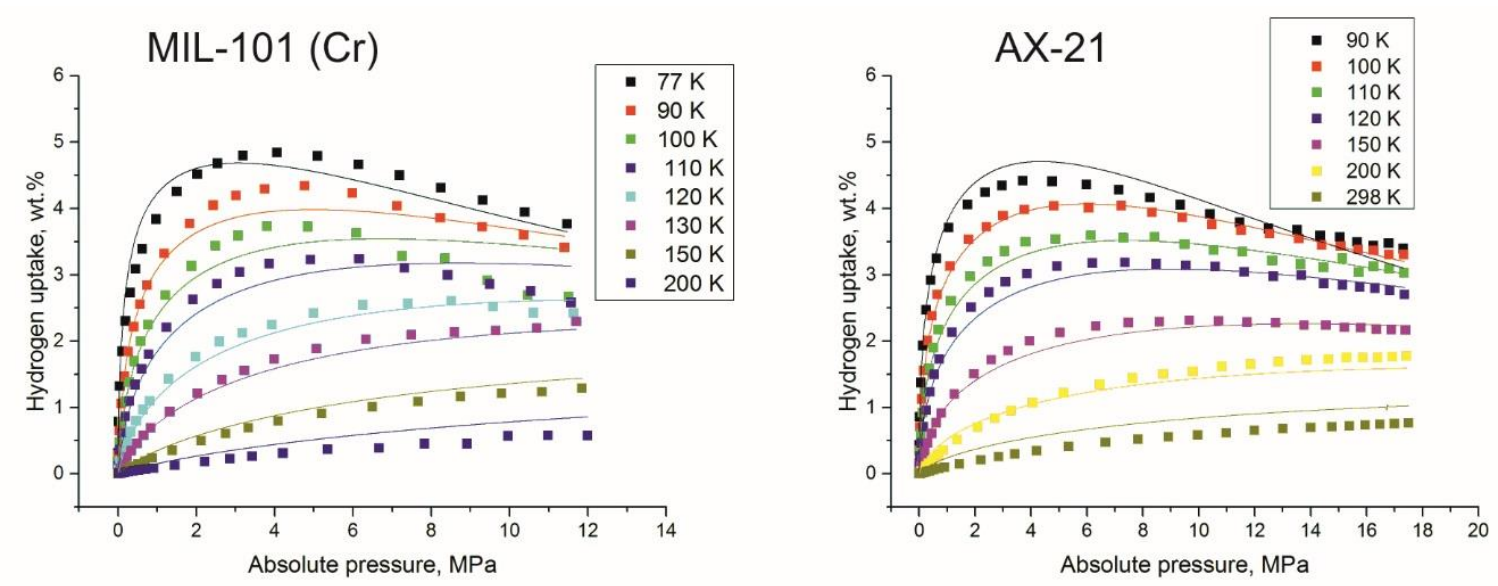

Figure 1 - Hydrogen excess isotherms on MIL-101 (Cr) and AX-21. The solid lines are the excess fits to the experimental points.

The parameters in eq.1 were determined using the non-linear fitting tool in Origin Pro 9.1, apart from the pore volume, which was fixed to the values obtained experimentally [23] using the Dubinin-Radushkevich (DR) method [40] on nitrogen isotherms at $77 \mathrm{~K}$. 
The parameters obtained from the fitting of eq. 1 to the excess hydrogen isotherms are shown in Table 1.

Table 1 - Fitting parameters for the hydrogen isotherms on MIL-101 (Cr) and the AX-21. The \pm uncertainly refers to the

\begin{tabular}{|c|c|c|}
\hline & MIL-101 (Cr) & AX-21 \\
\hline $\begin{array}{c}\text { Adsorbate density, } \rho_{\mathrm{a}} \\
/ \\
\mathrm{kg} \mathrm{m}^{-3}\end{array}$ & $88.0 \pm 2.0$ & $71.7 \pm 1.2$ \\
\hline $\begin{array}{c}\text { Micropore volume, } \\
\qquad V_{\mathrm{p} /} \\
\mathrm{cm}^{3} \mathrm{~g}^{-1}\end{array}$ & 0.81 & 1.97 \\
\hline $\begin{array}{c}\text { Tóth energy } \\
\text { parameter, } Q_{\text {st }} / \\
\text { kJ mol }{ }^{-1}\end{array}$ & $5.49 \pm 0.10$ & $6.36 \pm 0.09$ \\
\hline $\begin{array}{l}\text { Tóth entropy } \\
\text { parameter, } b_{0} / \\
\mathrm{MPa}^{-1}\end{array}$ & $3.28 \times 10^{-3} \pm 3.9 \times 10^{-4}$ & $6.21 \times 10^{-3} \pm 7.2 \times 10^{-4}$ \\
\hline $\begin{array}{c}\text { Tóth dimensionless } \\
\text { heterogeneity } \\
\text { parameter, } c\end{array}$ & $0.47 \pm 0.02$ & $0.26 \pm 0.01$ \\
\hline
\end{tabular}

The determined parameters show a very high adsorbed density for the hydrogen in both materials, which for the MIL-101 (Cr) is even higher than density of solid hydrogen at $4 \mathrm{~K}$ and $0 \mathrm{MPa}(87$ $\mathrm{kg} \mathrm{m}^{-3}$ ) [12]. For the AX-21, the adsorbed density is within the liquid hydrogen range (33 to $77 \mathrm{~kg} \mathrm{~m}^{-3}$ ). Recently and applying the same methodology, the same materials showed adsorbed densities for methane that were also very close to liquid methane [23]. It should also be noted that, in this case, the pore volume used in the fitting is the one determined from the DR method on a nitrogen isotherm at $77 \mathrm{~K}$. Hydrogen is a smaller molecule than nitrogen and there is some evidence that it might result in a larger available pore volume than nitrogen, which would influence the value obtained for the adsorbed density [41]. The heterogeneity parameter in the Tóth equation refers to the structural or chemical heterogeneity of the surface. It varies between 0 and 1, in which 
1 is a completely homogeneous surface, hence reducing the Tóth equation to the Langmuir equation.

\section{Cryocharging capacities}

The quantities stored using cryocharging for the two materials and the empty cylinder were compared. For the hybrid systems, the total adsorption determined from eq. 3 was used to calculate the total amount of hydrogen present in the cylinder. The first scenario involved the calculation of the quantity of hydrogen present at $77 \mathrm{~K}$ and $0.1 \mathrm{MPa}$ and the final pressure at $298 \mathrm{~K}$, assuming the cylinder is empty, half full (50\% of volume occupied) of adsorbent or completely full of adsorbent. The results are shown in Figure 2.
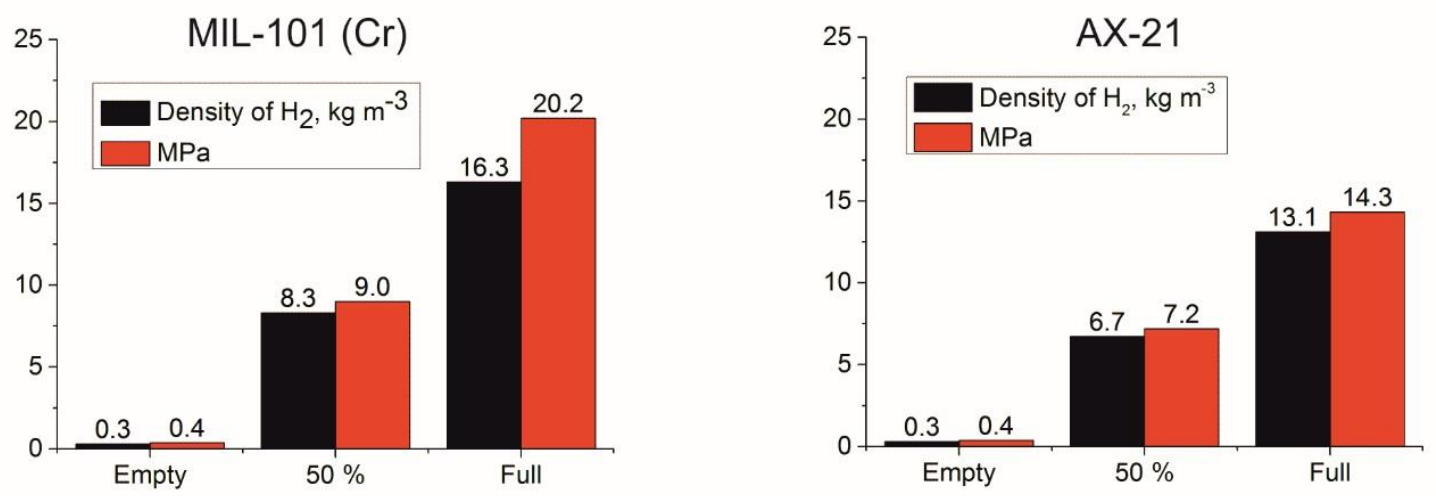

Figure 2 - Cryocharging at $77 \mathrm{~K}$ and $0.1 \mathrm{MPa}$, with volumetric densities and final pressures at $298 \mathrm{~K}$ for an empty container, half full and completely full of adsorbent. The adsorbents are the MIL-101 (Cr) and the AX-21.

As it can be seen in Figure 2, cryocharging with a cylinder completely full of adsorbent yields a volumetric density of $16.3 \mathrm{~kg} \mathrm{~m}^{-3}$ for the MIL-101 (Cr) and $13.1 \mathrm{~kg} \mathrm{~m}^{-3}$ for the AX-21, with a calculated final pressure in the cylinder of 20.2 and $14.3 \mathrm{MPa}$, respectively. The volumetric densities refer only to the internal volume of the cylinder, considering the total amount of hydrogen and the volume occupied by the adsorbent. This shows better performance than the empty cylinder, in which only $0.3 \mathrm{~kg} \mathrm{~m}^{-3}$ of hydrogen can stored at the same conditions, with a final pressure at $298 \mathrm{~K}$ of $0.4 \mathrm{MPa}$. 
The next comparison was to emulate the densities of hydrogen in 35 and $70 \mathrm{MPa}$ cylinders for hybrid systems and comparing the cryocharging performance. The densities of hydrogen at $298 \mathrm{~K}$ in 35 and $70 \mathrm{MPa}$ cylinders are $23.3 \mathrm{~kg} \mathrm{~m}^{-3}$ and $39.2 \mathrm{~kg} \mathrm{~m}^{-3}$, respectively. In Figure 3, the initial and final pressures needed to charge with a density equal to a 35 and $70 \mathrm{MPa}$ cylinder for systems that are completely full of adsorbent, have $50 \%$ of their volume in solid adsorbent and empty.

Charging pressure at $77 \mathrm{~K}$

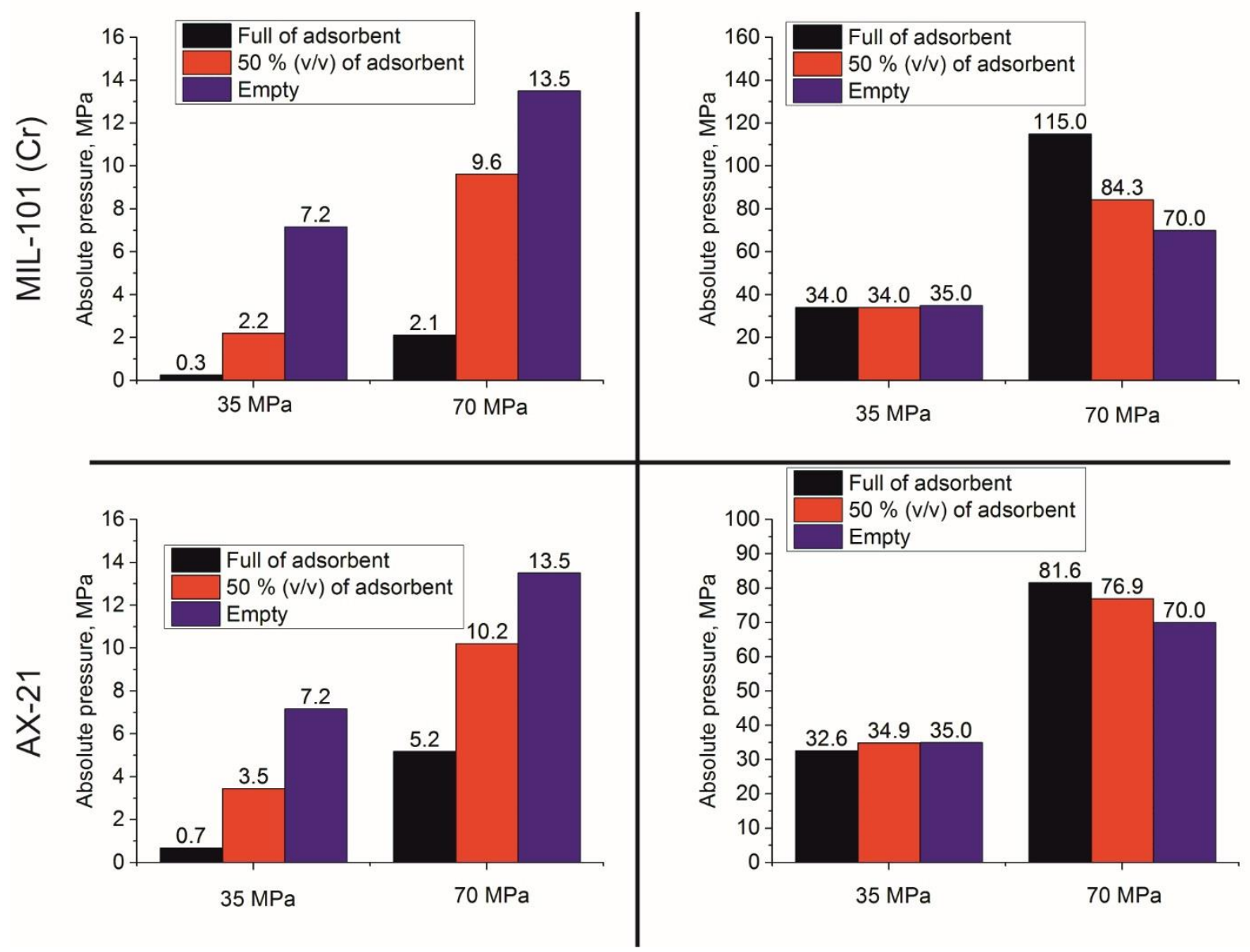

Figure 3 - Cryocharging at $77 \mathrm{~K}$ to obtain a density equal to a 35 or $70 \mathrm{MPa}$ high-pressure cylinder. On the left-hand side, the charging pressures at $77 \mathrm{~K}$, on the right-hand side the final pressures at $298 \mathrm{~K}$. The MIL-101 (Cr) is on top and the AX-21 is below.

Figure 3 shows a more complex picture for cryocharging in hybrid systems. For containers full of adsorbents, in both cases, the required charging pressures are much lower in comparison with an empty tank, as the container full of MIL-101 (Cr) only needs $0.3 \mathrm{MPa}$ and the container full of AX-21 only needs $0.7 \mathrm{MPa}$, both at $77 \mathrm{~K}$, to obtain a density of $23.3 \mathrm{~kg} \mathrm{~m}^{-3}$. The final pressure at 
$298 \mathrm{~K}$ for the MIL-101 (Cr) hybrid cylinder is $34.0 \mathrm{MPa}$ and for the AX-21 is $32.6 \mathrm{MPa}$, which is below the pressure in an empty tank for equal hydrogen densities, which is $35 \mathrm{MPa}$. This is possible because the break-even pressure is below $35 \mathrm{MPa}$ for both adsorbents [16, 17], meaning that cryocharging is an interesting strategy, as the pressure needed for charging at $77 \mathrm{~K}$ is lower by a factor of 27 and 10 for the MIL-101 (Cr) and AX-21, respectively, and the final pressure is below the final pressure of an empty tank at $298 \mathrm{~K}$, which is $35 \mathrm{MPa}$.

For densities equal to $70 \mathrm{MPa}$ cylinders $\left(39.2 \mathrm{~kg} \mathrm{~m}^{-3}\right)$, the adsorbents still represent an advantage in charging pressures, as the tank full of MIL-101 (Cr) only needs $2.1 \mathrm{MPa}$ and the AX-21 only needs 5.2 MPa, compared to 13.5 MPa needed for the empty cylinder. However, the final pressures, as $70 \mathrm{MPa}$ is above the break-even pressures for both adsorbents, are higher than the final pressure of the empty cylinder (70 MPa). For the MIL-101 (Cr), the final pressure at $298 \mathrm{~K}$ is $115 \mathrm{MPa}$ and for the AX-21 is $81.6 \mathrm{MPa}$, which could represent increased costs in cylinder design (as they have to withstand higher pressures) and an additional safety concern.

\section{Calculating working capacities}

Designing hybrid systems that deliver hydrogen at vacuum represents an energy loss, as there is an energy penalty involved in sub-atmospheric pressures. Taking this into account, the working capacities for hydrogen storage in both systems (AX-21 and MIL-101 (Cr)) were investigated, from $77 \mathrm{~K}$ to room temperature. The working capacities were calculated by determining the total uptake at the charging pressure (two charging pressures were used, 6.5 and 3.5 MPa) and subtracting the total uptake at the delivery pressure $(0.5 \mathrm{MPa})$. The results are in Figure 4. 

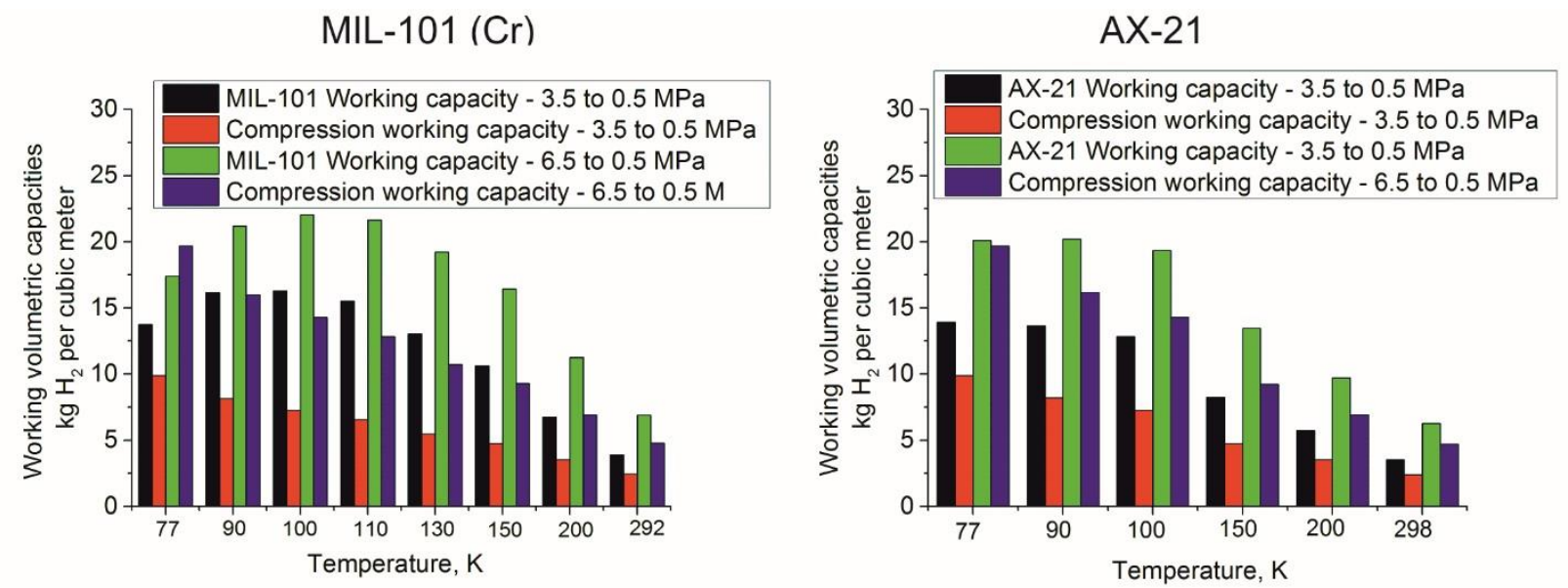

Figure 4 - Working volumetric capacities for the MIL-101 (Cr) and the AX-21, from $77 \mathrm{~K}$ to room temperature, calculated assuming a delivery pressure of $0.5 \mathrm{MPa}$ and a charging pressure of both 3.5 and $6.5 \mathrm{MPa}$.

The results in Figure 4 show that, when considering the working volumetric capacities for these charging and delivery pressures, there is little advantage in using hybrid systems with adsorbents. The working capacity at $77 \mathrm{~K}$ for the MIL-101 (Cr) with a charging pressure of $3.5 \mathrm{MPa}$ yields $\sim 14 \mathrm{~kg} \mathrm{~m}^{-3}$ of stored hydrogen, which compares with $\sim 10 \mathrm{~kg} \mathrm{~m}^{-3}$ for an empty cylinder. When considering 6.5 MPa as the charging pressure at $77 \mathrm{~K}$, the MIL-101 (Cr) displays $\sim 17.5 \mathrm{~kg} \mathrm{~m}^{-3}$ of volumetric working capacity, which is slightly less than the working volumetric capacity at the same conditions for an empty cylinder $\left(\sim 20 \mathrm{~kg} \mathrm{~m}^{-3}\right)$. The AX-21 shows the same working capacities at $3.5 \mathrm{MPa}$ at $77 \mathrm{~K}$, with $\sim 14 \mathrm{~kg} \mathrm{~m}^{-3}$ with adsorbent and $\sim 10 \mathrm{~kg} \mathrm{~m}^{-3}$ without adsorbent. At the same temperature and using a charging pressure of $6.5 \mathrm{MPa}$, the $\mathrm{AX}-21$ shows roughly the same working volumetric capacity as the empty cylinder, with both having a value of $\sim 20 \mathrm{~kg} \mathrm{~m}^{-3}$. The working volumetric capacities are based on the difference of amount at 3.5 or $6.5 \mathrm{MPa}$ and $0.5 \mathrm{MPa}$, so they are very dependent on the shape of the isotherm and a large uptake at lower pressures (below 0.5 MPa) will not influence the deliverable amounts. In Figure 4, the MIL-101 (Cr) shows a growing working capacity up to $100 \mathrm{~K}$, for both the 6.5 and $3.5 \mathrm{MPa}$ charging pressures, with diminishing capacities afterwards. The AX-21 shows working capacities at 77 and $90 \mathrm{~K}$ that are close and then diminish with increasing temperature. It should be noted that the compressive working capacities, which are calculated for empty cylinders, are the same in both graphs. The overall conclusion from Figure 4 is that, considering these loading and delivery pressures, hybrid systems do not represent significant gains in uptake over empty cylinders at these conditions and they are adding additional weight to the system. 


\section{Adsorption kinetics}

Another important requirement for solid-state storage materials are the charging times of hydrogen, so the mass transfer in these materials was investigated at the same conditions considered in this work - high-pressures and cryogenic temperatures. Kinetic data, which consists of uptakes as a function of time for all the isotherm points is available from the Hiden HTP-1 volumetric gas sorption analyser. Along with the gas uptake as a function of time, sample pressures and temperatures are also tracked in real-time, and Figure 5 shows the molar uptake, sample pressure and sample temperature for the MIL-101 (Cr) at $77 \mathrm{~K}$ for the first two pressure steps $(\sim 0.06$ and $\sim 0.15 \mathrm{MPa})$.

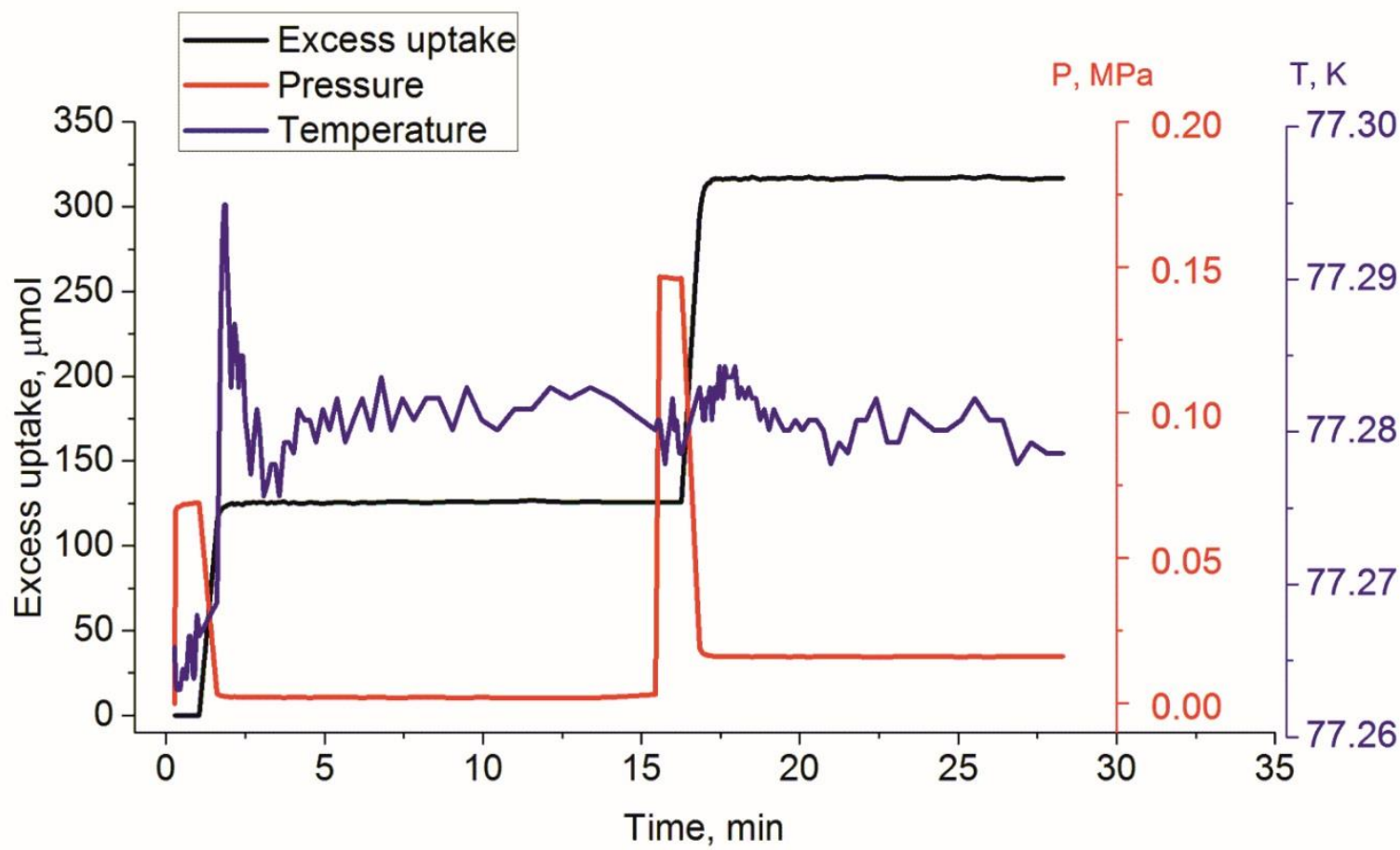

Figure 5 - Pressure, uptake and temperature as a function of time on MIL-101 (Cr) at 77 K on the first two pressure steps (0.06 and $0.15 \mathrm{MPa})$. The black $\mathrm{y}$-axis on the left-hand side is uptake in $\mu \mathrm{mol}$ and the two $\mathrm{y}$-axis on the right-hand side are the pressure (in red, MPa) and the temperature (blue, K).

Figure 5 shows the first two pressure steps for hydrogen isotherm in MIL-101 (Cr) at $77 \mathrm{~K}$, showing the hydrogen uptake (in $\mu \mathrm{mol}$ ), the pressure (in $\mathrm{MPa}$ ) and the sample temperature in $\mathrm{K}$ as a function of time (in minutes). Adsorption is an exothermic process, so heat will be released into 
the system immediately as the uptake increases and this can be seen in the figure, with an increase in sample temperature upon adsorption at 2 mins and again at 16 mins. This variation in temperature is minimal, as in the Hiden HTP-1, the $77 \mathrm{~K}$ isotherm is measured in an immersion reactor full of liquid nitrogen, resulting in excellent temperature control with an almost unnoticeable temperature variation for each pressure step, as seen in the figure. Another conclusion to draw is that, at least for the first two pressure steps, the kinetics seem to be extremely rapid, as the uptake quickly increases upon the pressure step and reaches equilibrium in under 2 minutes.

Diffusion processes are usually described using Fick's law of diffusion, which states that the rate of transfer of a substance through a cross-sectional area is proportional to the concentration gradient along the normal vector of that area [37]. Fickian diffusion has been widely used to describe adsorption kinetics, but modelling adsorption processes using strict Fickian models can result in complex mathematical formulations [42]. The Linear Driving Force model (LDF), which was introduced by Glueckauf and Coates [35, 36], has been used extensively in the literature to measure macroscopic, non-equilibrium diffusion and extract effective intraparticle (also known as transport) diffusivities [43]. The LDF model has the distinct advantage of being simple and physically consistent, and has been applied to analyse adsorption kinetics in a variety of materials [38], including in non-isothermal adsorption kinetics [38]. The integration of the LDF model shown in eq. 7 can be applied to the analysis of the kinetic data for each pressure step, to extract the mass transfer coefficients and determine the effective intraparticle diffusion of hydrogen in AX-21 and MIL-101 (Cr) at cryogenic temperatures and up to $18 \mathrm{MPa}$.

Figure 6 shows the hydrogen uptake in $\mu \mathrm{mol}$ as a function of time fitted using the integrated form of the linear driving force model in eq. 7. The sample temperature is shown in the right-hand side axis, in blue and in $\mathrm{K}$. 

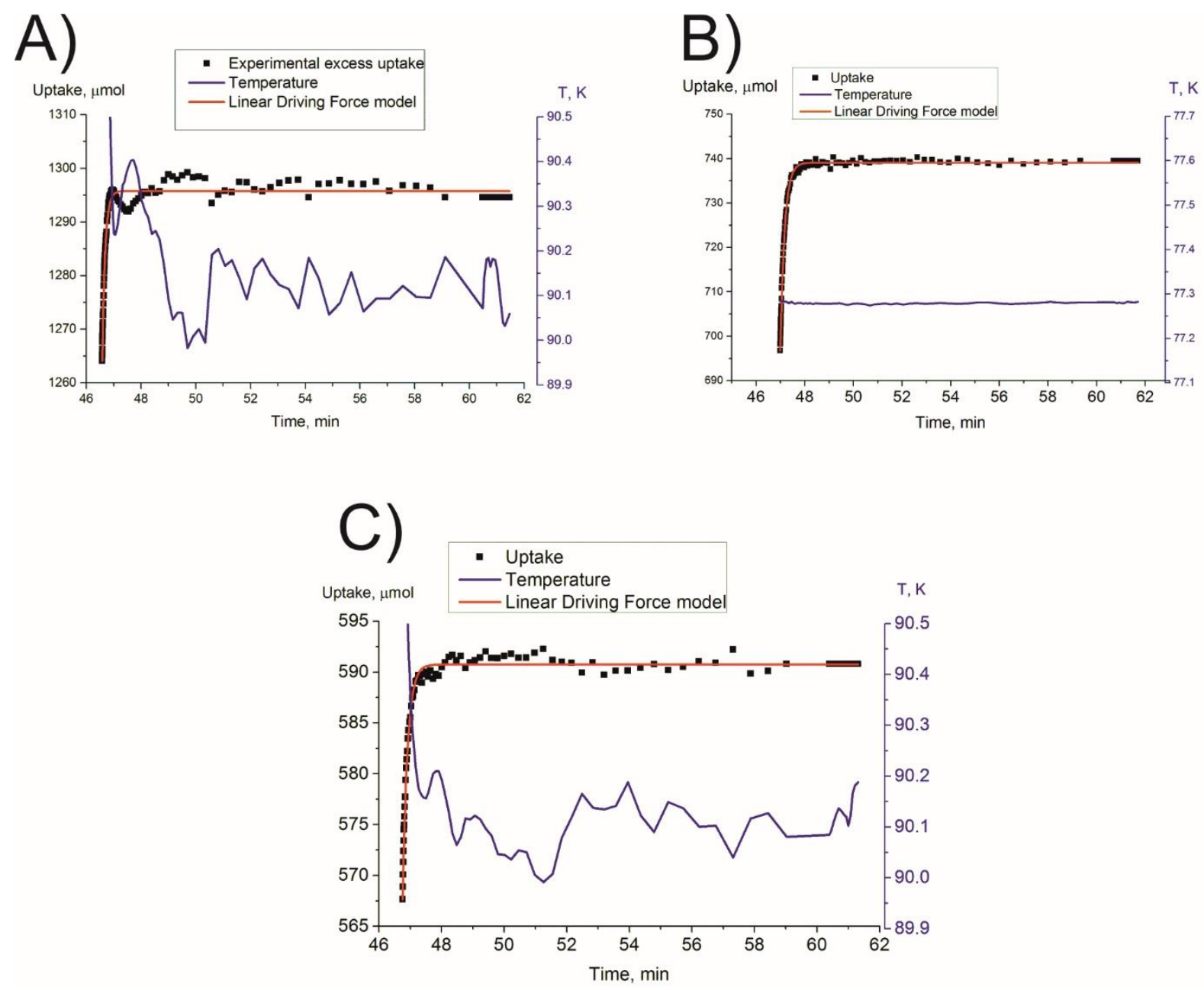

Figure 6 - Kinetic data (black dots) for the AX-21 at 90 K (A), MIL-101 (Cr) at 77 (B) and 90 K (C) for the $4^{\text {th }}$ pressure step (0.66, 1.11 and 1.62 MPa, respectively). The data was fitted using a linear driving force model (red line). The sample temperature is shown in $\mathrm{K}$ (blue line).

For each pressure step, the linear driving force model was modelled on the kinetic data, using $n_{0}$ and $t_{0}$ as the initial points at which a change was observed on the molar uptake upon the pressure change. The parameters determined from the individual fits were $n_{2}$ (the equilibrium molar uptake) and $k$, the mass transfer coefficient (MTC) in the LDF model. The dispersion of values and the corresponding fits to the kinetic data varied, but they were consistently better in data that did not display great temperature variation. All the fits of the LDF model to each pressure step for the MIL-101 (Cr) at 77 and $90 \mathrm{~K}$ and for the AX-21 at $90 \mathrm{~K}$ are shown in Supporting Information. To assess the quality of fits to the kinetic data, the adjusted coefficient of correlation (adjusted $R^{2}$ ) was calculated for the individual fits and a graph with its values as a function of the pressure step 
is shown in Supporting Information for the AX-21 at $90 \mathrm{~K}$ and for the MIL-101 (Cr) at 77 and 90 K. The MTCs in the LDF model are shown in Figure 7.

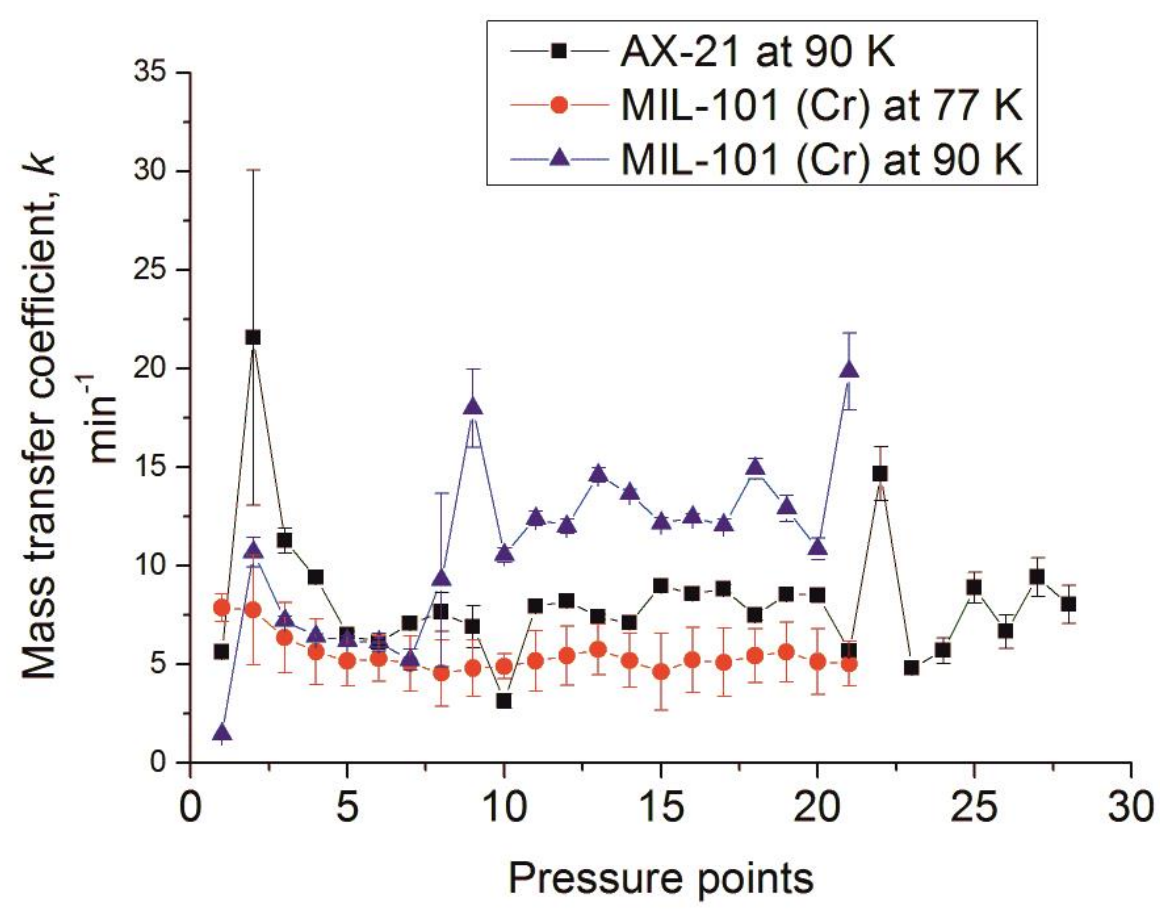

Figure 7 - Mass transfer coefficients for all pressure steps from AX-21 at $90 \mathrm{~K}$ and MIL-101 (Cr) at 77 and $90 \mathrm{~K}$ calculated using eq.7 (error bars correspond to the standard error from the nonlinear fitting).

There is a greater variability at $90 \mathrm{~K}$ for both materials, which is indicative of the influence of temperature on the mass transfer. Transient uptake rate measurements are subject to heat transfer limitations, as noted before and illustrated in this data [44]. In the MIL-101 (Cr) at $77 \mathrm{~K}$, where the sample temperature is much more carefully controlled, the variation is minimal, with MTC varying between 4 and $7 \mathrm{~min}^{-1}$. For the same material at $90 \mathrm{~K}$, the values for the MTC range between 1 and $19 \mathrm{~min}^{-1}$. If outliers are excluded, most of the values will fall between 7 and $14 \mathrm{~min}^{-1}$. The MTC for the AX-21 at $90 \mathrm{~K}$ range between 3 and $21 \mathrm{~min}^{-1}$ but again, if outliers are excluded, most values will fall between 5 and $9 \mathrm{~min}^{-1}$.

The correction for volumetric systems, which is built into eq. 8 and accounts of the fraction of gas in the adsorptive which is adsorbed at each pressure step, was also calculated. The difficulty in this approach is that, with increasing pressures, this fraction will diminish and should only be accounted when it is very significant. The initial and final pressures were used to calculate the 
fraction of gas in the adsorptive which is taken up by the adsorbate. The calculated $\Lambda$ values are all very low, as at very high pressures, the fraction of gas in the adsorptive that is adsorbed in the pore is residual, as saturation is reached and only small quantities are adsorbed. Our calculations show that $\Lambda$ is less than 0.30 in all materials after only $5 \mathrm{MPa}$. At higher pressures, calculated $\Lambda$ is even smaller, with a value of around 0.10 at $11 \mathrm{MPa}$ for the MIL-101 $(\mathrm{Cr})$ and a value of 0.04 for the AX-21 at $16 \mathrm{MPa}$. As the MTC is calculated by factoring the $\Lambda$, and this is very low at high pressures, the results are significantly affected. A figure with the corrected MTC is shown in the Supplementary Information.

As shown by Glueckauf and others [35, 36], the MTC in the LDF model can be related to the effective intraparticle diffusivities, assuming a spherical particle and using a particle radius $R_{\mathrm{p}}$. The equation that relates the MTC in the LDF model and the diffusivities is shown in eq. 9.

$$
k=15 \frac{D}{R_{p}^{2}}
$$

where $D$ is the effective intraparticle (or transport) diffusivity. The average particle diameter for both the AX-21 and MIL-101 (Cr) was taken from SEM imaging (Fig. 8). The SEM micrographs shown in Figure 8 were treated with Image $\mathbf{J}$ [39] to determine an average particle diameter. The treated image and the determination of the particle radius from SEM are shown in Supplementary Information.
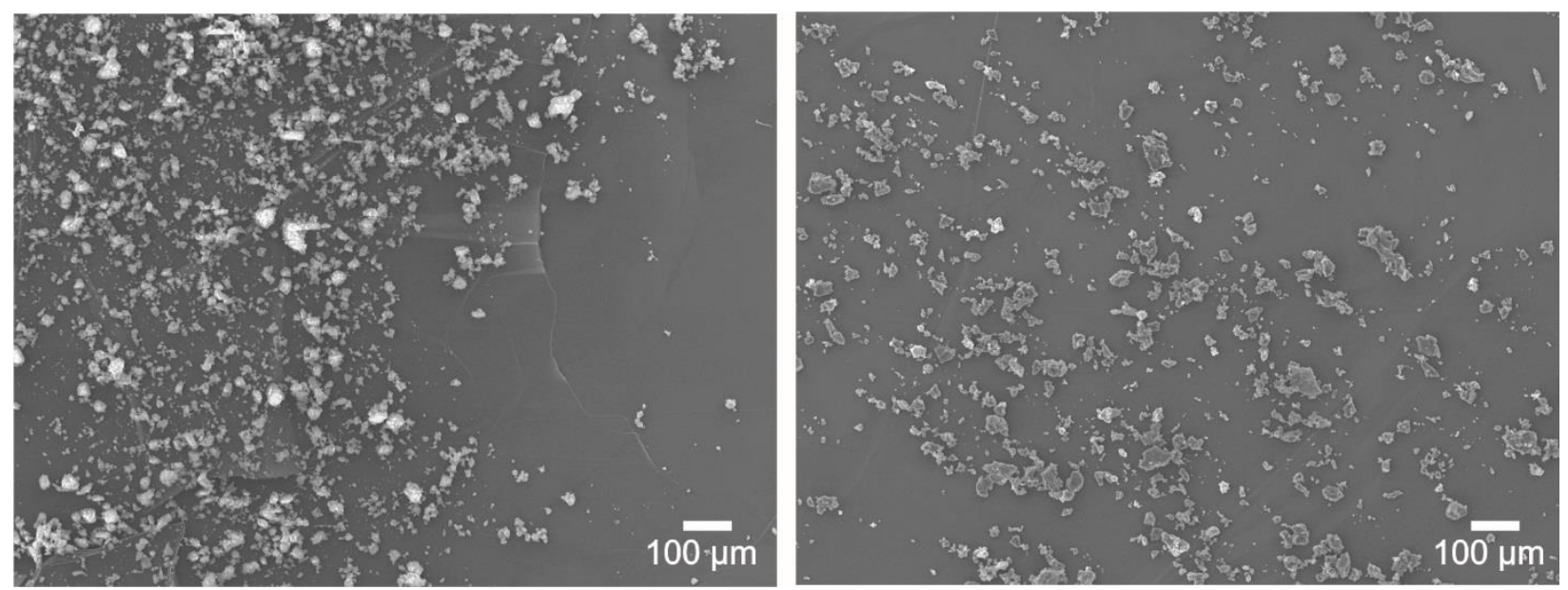

Figure 8 - SEM micrographs of MIL-101 (Cr) (left) and AX-21 (right). 
The diffusivities were calculated using eq. 9 assuming a spherical particle and calculating the particle radius from the particle area of Image $\mathrm{J}$. The mean particle radius were determined at 3.55 $\mu \mathrm{m}$ for the AX-21 and $5.57 \mu \mathrm{m}$ for the MIL-101 (Cr). The MTC were averaged for each temperature and across the pressure range. In Table 2, the mean MTC across all pressures for each temperature, where the uncertainty is the standard deviation and the calculated diffusivities.

Table 2 - Fitting parameters for the hydrogen isotherms on MIL-101 (Cr) and the AX-21. The error \pm uncertainty refers to the standard error from the nonlinear fitting.

\begin{tabular}{|c|c|c|c|}
\hline & $\begin{array}{c}\text { Mean MTC } \\
\text { min }^{-1}\end{array}$ & $\begin{array}{c}\text { Particle radius } \\
\mu \mathrm{m}\end{array}$ & $\begin{array}{c}\text { Effective diffusivity } \\
\mathrm{m}^{2} \mathrm{~s}^{-1}\end{array}$ \\
\hline AX-21, 90 K & $\mathbf{8 . 2 3} \pm 3.36$ & 5.57 & $3.24 \times 10^{-8}$ \\
\hline MIL-101 (Cr), 77 K & $5.47 \pm 0.87$ & 3.55 & $2.15 \times 10^{-8}$ \\
\hline MIL-101 (Cr), 90 K & $10.09 \pm 4.37$ & 3.55 & $6^{-24} \times 10^{-8}$ \\
\hline
\end{tabular}

Effective diffusivities (or transport diffusivities) can be estimated from macroscopic methods and also from molecular simulations. Molecular simulations usually calculate the self- (or tracer) diffusivity, which can then be related to the transport diffusivity using the corrected diffusivity [45]. Hydrogen transport diffusivities in metal-organic framework [ $\left.\mathrm{Zn}(\mathrm{bdc})(\text { ted })_{0.5}\right]$ at $77 \mathrm{~K}$ calculated using the correction to the self-diffusivity obtained from molecular simulations showed values that ranged between $\sim 1 \times 10^{-8}$ and $1 \times 10^{-7} \mathrm{~m}^{2} \mathrm{~s}^{-1}$ [46]. High values for hydrogen selfdiffusivities were observed experimentally using quasielastic neutron scattering for metal-organic frameworks, in which a value of $2 \times 10^{-6}$ is extrapolated for the self-diffusivity at $77 \mathrm{~K}$ for the MIL-47 (V) [47]. The values from Table 2 are comparable to diffusivities of deuterium in zeolite $\mathrm{NaX}$, which showed a value of $\sim 3.5 \times 10^{-8} \mathrm{~m}^{2} \mathrm{~s}^{-1}$ for the calculated transport diffusivity at $100 \mathrm{~K}$ from quasielastic neutron scattering measurements [45]. High sorption diffusivities are needed, as one of the hydrogen storage system requirements is the charging time, which in the US DOE hydrogen storage materials' targets should be kept under $3.3 \mathrm{~min}$ (2020 target) and $2.5 \mathrm{~min}$ (ultimate target) for a complete system fill of $5 \mathrm{~kg}$ of hydrogen [48].

Micropore materials are the ones with the most affinity for hydrogen, with ultramicroporous materials (with pore sizes of $0.6-0.7 \mathrm{~nm}$ ) shown to be the most effective for hydrogen adsorption. Diffusion of some gases in very small pores can be slow, which could turn problematic for applications. For the operating storage conditions that are likely to be used for hydrogen storage 
in porous materials (cryogenic temperatures and high pressures), the calculated mass transfer coefficients and effective diffusivities for these materials and the results shown indicate the equilibrium in porous materials can be achieved at these conditions in minutes for most cases. This, added to the reversibility offered by adsorbent materials, are important when comparing to other hydrogen storage materials (for instance, metal hydrides), which suffer from reversibility and kinetic issues and might help to build a stronger case for adsorbent-based hydrogen storage materials in mobile applications.

\section{Conclusions}

The hydrogen and fuel cell combination is one of the most interesting alternatives for energy efficient transport, as fuel cell systems are inherently more efficient than internal combustion engines, and they present advantages that include no greenhouse gas emissions at point of use and the possibility of producing the hydrogen from a variety of sustainable sources. Storing hydrogen for mobile applications has consisted so far on using compressed systems, which typically operate at 35 or $70 \mathrm{MPa}$. These conditions carry safety and efficiency concerns and alternative storage technologies have been suggested. A number of different classes of hydrogen storage materials have been proposed as alternatives to compressed storage, as these can increase the volumetric density of hydrogen in mobile vehicles while diminishing the operating pressures.

Hybrid hydrogen storage cylinders with adsorbents have features that make them attractive solutions to incorporate in mobile applications. Designing these systems can be a real challenge, as in-depth knowledge of their structural, chemical and material properties is required. The requirements for solid-state hydrogen materials are stringent, and range across needs from fast kinetics, high volumetric and gravimetric densities, cyclability, and many others. Loading hydrogen at cryogenic temperatures (cryocharging) can diminish the compression costs and it is here suggested as a possible engineering alternative. The fact that cylinders are then returned to ambient temperatures means that no special insulation is needed. This study shows that the use of adsorbents can substantially lower the charging pressures needed, with only 0.3 and $0.7 \mathrm{MPa}$ needed for tanks full of MIL-101 (Cr) and the AX-21, respectively, to charge at $77 \mathrm{~K}$ and obtain a volumetric density at $298 \mathrm{~K}$ equal to a $35 \mathrm{MPa}$ high-pressure cylinder. This compares with 7.2 MPa needed in the empty cylinder case. For densities equal to $70 \mathrm{MPa}$, adsorbents are detrimental 
to performance, as they increase storage pressures at $298 \mathrm{~K}$ to 115 and 81.6 using MIL-101 $(\mathrm{Cr})$ and $\mathrm{AX}-21$, respectively, creating a safety issue. The volumetric working capacities for both materials were also investigated, with the results showing little advantage in using adsorbents for loading pressures of 6.5 or $3.5 \mathrm{MPa}$ and a delivery pressure of $0.5 \mathrm{MPa}$. The kinetics for highpressure and cryogenic temperatures were also investigated using the linear driving force model, with the experimentally determined effective intraparticle (or transport) diffusivities calculated in these materials at these conditions showing values of $3.24 \times 10^{-8} \mathrm{~m}^{2} \mathrm{~s}^{-1}$ for the AX-21 at $90 \mathrm{~K}$, and $2.15 \times 10^{-8} \mathrm{~m}^{2} \mathrm{~s}^{-1}$ and $6.24 \times 10^{-8} \mathrm{~m}^{2} \mathrm{~s}^{-1}$ for the MIL-101 (Cr) at 77 and $90 \mathrm{~K}$, respectively.

\section{Supplementary Information}

The Supporting Information includes all the linear driving force fits for the kinetic data, the statistical coefficients for the different materials and temperatures that were considered, the corrected mass transfer coefficient and the treatment of the SEM images in ImageJ. All the data used in this article is available and can be accessed at no charge from the University of Bath Data Archive at http://dx.doi.org/10.15125/BATH-00099. The data includes the raw isotherm and kinetic data in an Excel file, the OriginPro file with the analysis and the fittings and the SEM imaging and Image $J$ treatment. The kinetic data includes the molar uptake, the sample temperature and the pressure as a function of time. Any queries relating the data should be addressed to the corresponding author.

\section{Acknowledgements}

NB and TJM would like to thank the UK Engineering and Physical Science Research Council (EPSRC) for funding through three Hydrogen and Fuel Cells SUPERGEN grants (EP/L018365/1, EP/K021109/1 and EP/J016454/1). JES would like to thank the EPSRC Centre for Doctoral Training Centre in Sustainable Chemical Technologies at the University of Bath (EP/G03768X/1) and to Airbus Group Innovation, Munich, Germany, for financial support. VPT thanks the University of Bath for a Prize Research Fellowship and acknowledges funding from the European Regional Development Fund (ERDF) INTERREG IV programme for Materials for Energy Efficiency in Transport (MEET). 


\section{References}

[1] IPCC. Climate Change 2014: Synthesis Report. Contribution of Working Groups I, II and III to the Fifth Assessment Report of the Intergovernmental Panel on Climate Change Geneva, Switzerland: IPCC, Geneva, Switzerland; 2014. p. 151.

[2] Edwards PP, Kuznetsov VL, David WIF. Hydrogen energy. Philosophical Transactions of the Royal Society a-Mathematical Physical and Engineering Sciences. 2007;365:1043-56.

[3] McNicol BD, Rand DAJ, Williams KR. Fuel cells for road transportation purposes - yes or no? Journal of Power Sources. 2001;100:47-59.

[4] Sartbaeva A, Kuznetsov VL, Wells SA, Edwards PP. Hydrogen nexus in a sustainable energy future. Energy \& Environmental Science. 2008;1:79-85.

[5] Häussinger P, Lohmüller R, Watson AM. Hydrogen. Ullmann's Encyclopedia of Industrial Chemistry: Wiley-VCH Verlag GmbH \& Co. KGaA; 2000.

[6] Haynes WM, Lide DR. CRC handbook of chemistry and physics : a ready-reference book of chemical and physical data. 92nd ed., 2011-2012 / editor-in-chief, W.M. Haynes ; associate editor, David R. Lide. ed. Boca Raton, Fla. ; London: CRC; 2011.

[7] Gosselink JW. Pathways to a more sustainable production of energy: sustainable hydrogen - a research objective for Shell. International Journal of Hydrogen Energy. 2002;27:1125-9.

[8] Cherryman SJ, King S, Hawkes FR, Dinsdale R, Hawkes DL. An exploratory study of public opinions on the use of hydrogen energy in Wales. Public Understanding of Science.

2008;17:397-410.

[9] Fayaz H, Saidur R, Razali N, Anuar FS, Saleman AR, Islam MR. An overview of hydrogen as a vehicle fuel. Renewable \& Sustainable Energy Reviews. 2012;16:5511-28.

[10] Leachman JW, Jacobsen RT, Penoncello SG, Lemmon EW. Fundamental Equations of State for Parahydrogen, Normal Hydrogen, and Orthohydrogen. Journal of Physical and Chemical Reference Data. 2009;38.

[11] Wagner W, Pruß A. The IAPWS Formulation 1995 for the Thermodynamic Properties of Ordinary Water Substance for General and Scientific Use. Journal of Physical and Chemical Reference Data. 2002;31:387-535.

[12] Silvera IF. The Solid Molecular Hydrogens in the Condensed Phase - Fundamentals and Static Properties. Reviews of Modern Physics. 1980;52:393-452.

[13] Yamashita A, Kondo, M., Goto, S., and Ogami, N. Development of High-Pressure Hydrogen Storage System for the Toyota "Mirai". SAE Technical Paper. 2015:1169.

[14] David WIF. Effective hydrogen storage: a strategic chemistry challenge. Faraday Discussions. 2011;151:399-414.

[15] US Department of Energy, Annual Merit Review, http://www.annualmeritreview.energy.gov/, Accessed May 2015.

[16] Bimbo N, Ting VP, Sharpe JE, Mays TJ. Analysis of optimal conditions for adsorptive hydrogen storage in microporous solids. Colloids and Surfaces a-Physicochemical and Engineering Aspects. 2013;437:113-9.

[17] Hardy B, Corgnale C, Chahine R, Richard MA, Garrison S, Tamburello D, et al. Modeling of adsorbent based hydrogen storage systems. International Journal of Hydrogen Energy.

2012;37:5691-705.

[18] Eberle U, Felderhoff M, Schuth F. Chemical and Physical Solutions for Hydrogen Storage. Angewandte Chemie-International Edition. 2009;48:6608-30.

[19] Rouquerol F, Rouquerol J, Sing KSW. Adsorption by powders and porous solids : principles, methodology and applications. San Diego, Calif. ; London: Academic Press; 1999. 
[20] Latroche M, Surble S, Serre C, Mellot-Draznieks C, Llewellyn PL, Lee JH, et al. Hydrogen storage in the giant-pore metal-organic frameworks MIL-100 and MIL-101. Angewandte Chemie-International Edition. 2006;45:8227-31.

[21] Ferey G, Serre C, Mellot-Draznieks C, Millange F, Surble S, Dutour J, et al. A hybrid solid with giant pores prepared by a combination of targeted chemistry, simulation, and powder diffraction. Angewandte Chemie-International Edition. 2004;43:6296-301.

[22] Sharpe JE, Bimbo N, Ting VP, Burrows AD, Jiang DM, Mays TJ. Supercritical hydrogen adsorption in nanostructured solids with hydrogen density variation in pores. Adsorption-Journal of the International Adsorption Society. 2013;19:643-52.

[23] Bimbo N, Physick AJ, Noguera-Díaz A, Pugsley A, Holyfield LT, Ting VP, et al. High volumetric and energy densities of methane stored in nanoporous materials at ambient temperatures and moderate pressures. Chemical Engineering Journal. 2015;272:38-47. [24] Bimbo N, Sharpe JE, Ting VP, Noguera-Diaz A, Mays TJ. Isosteric enthalpies for hydrogen adsorbed on nanoporous materials at high pressures. Adsorption-Journal of the International Adsorption Society. 2014;20:373-84.

[25] NIST, NIST Chemistry WebBook, http://webbook.nist.gov/chemistry/, Accessed 12 November 2014.

[26] Sharpe JE, Bimbo N, Ting VP, Rechain B, Joubert E, Mays TJ. Modelling the potential of adsorbed hydrogen for use in aviation. Microporous and Mesoporous Materials. 2015;209:13540 .

[27] Bimbo N, Ting VP, Hruzewicz-Kolodziejczyk A, Mays TJ. Analysis of hydrogen storage in nanoporous materials for low carbon energy applications. Faraday Discussions. 2011;151:59-74. [28] Ting VP, Ramirez-Cuesta AJ, Bimbo N, Sharpe JE, Noguera-Diaz A, Presser V, et al.

Direct Evidence for Solid-like Hydrogen in a Nanoporous Carbon Hydrogen Storage Material at Supercritical Temperatures. ACS Nano. 2015; 9, (8): 8249-8254.

[29] Tóth J. Gas- (Dampf-) Adsorption an Festen Oberflachen Inhomogener Aktivitat .1. Acta Chimica Academiae Scientarium Hungaricae. 1962;30:415.

[30] Tóth J. Gas- (Dampf-) Adsorption an Festen Oberflachen Inhomogener Aktivitat .2. Acta Chimica Academiae Scientarium Hungaricae. 1962;31:393.

[31] Tóth J. Gas- (Dampf-) Adsorption an Festen Oberflachen Inhomogener Aktivitat .3. Acta Chimica Academiae Scientarium Hungaricae. 1962;32:39.

[32] Tóth J. Gas- (Dampf-) Adsorption an Festen Oberflachen Inhomogener Aktivitat .4. Acta Chimica Academiae Scientarium Hungaricae. 1962;33:153.

[33] Tóth J. State Equations of Solid-Gas Interface Layers. Acta Chimica Academiae Scientarium Hungaricae. 1971;69:311.

[34] Tóth J. A Uniform Interpretation of Gas-Solid Adsorption. Journal of Colloid and Interface Science. 1981;79:85-95.

[35] Glueckauf E. Theory of Chromatography .10. Formulae for Diffusion into Spheres and Their Application to Chromatography. Transactions of the Faraday Society. 1955;51:1540-51. [36] Glueckauf E, Coates JI. Theory of Chromatography .4. The Influence of Incomplete Equilibrium on the Front Boundary of Chromatograms and on the Effectiveness of Separation. Journal of the Chemical Society. 1947:1315-21.

[37] Ruthven DM. Principles of adsorption and adsorption processes. New York ; Chichester: Wiley; 1984.

[38] Sircar S, Hufton JR. Why does the Linear Driving Force model for adsorption kinetics work ? Adsorption-Journal of the International Adsorption Society. 2000;6:137-47. 
[39] Schneider CA, Rasband WS, Eliceiri KW. NIH Image to ImageJ: 25 years of image analysis. Nature Methods. 2012;9:671-5.

[40] Dubinin MM, Zaverina ED, Radushkevich LV. Sorbtsiya I Struktura Aktivnykh Uglei .1. Issledovanie Adsorbtsii Organicheskikh Parov. Zhurnal Fizicheskoi Khimii. 1947;21:1351-62. [41] Streppel B, Hirscher M. BET specific surface area and pore structure of MOFs determined by hydrogen adsorption at $20 \mathrm{~K}$. Physical Chemistry Chemical Physics. 2011;13:3220-2. [42] Crank J. The mathematics of diffusion. 2nd ed. ed. Oxford: Clarendon Press; 1975. [43] Patton A, Crittenden BD, Perera SP. Use of the linear driving force approximation to guide the design of monolithic adsorbents. Chemical Engineering Research \& Design. 2004;82:9991009 .

[44] Karge HG, Weitkamp J, Brandini S. Adsorption and diffusion. Berlin: Springer; 2008.

[45] Jobic H, Karger J, Bee M. Simultaneous measurement of self- and transport diffusivities in zeolites. Phys Rev Lett. 1999;82:4260-3.

[46] Liu J, Lee JY, Pan L, Obermyer RT, Simizu S, Zande B, et al. Adsorption and diffusion of hydrogen in a new metal-organic framework material: [Zn(bdc)(ted)(0.5)]. J Phys Chem C. 2008;112:2911-7.

[47] Salles F, Jobic H, Maurin G, Koza MM, Llewellyn PL, Devic T, et al. Experimental evidence supported by simulations of a very high $\mathrm{H}(2)$ diffusion in metal organic framework materials. Phys Rev Lett. 2008;100.

[48] US Department of Energy, Targets for Onboard Hydrogen Storage Systems for Light-Duty Vehicles, http://www1.eere.energy.gov/hydrogenandfuelcells/storage/pdfs/targets onboard hydro storage. pdf, Accessed October 2012 